\title{
The influence of laparoscopy-assisted gastrectomy versus open gastrectomy to long-term survival for early gastric cancer: an updated meta-analysis based on randomized controlled trials
}

\section{Zhao Zhai}

Tumor Hospital of Harbin Medical University

\section{Shenghan Lou}

Tumor Hospital of Harbin Medical University

\section{Ziyu Zhu}

Tumor Hospital of Harbin Medical University

\section{Xiliang Cong}

Tumor Hospital of Harbin Medical University

Jialiang Gao

Tumor Hospital of Harbin Medical University

\section{Bangling Han}

Tumor Hospital of Harbin Medical University

\section{Xin Yin}

Tumor Hospital of Harbin Medical University

\section{Yu Zhang}

Tumor Hospital of Harbin Medical University

Yingwei Xue ( $\nabla$ xueyingwei@hrbmu.edu.cn )

Tumor Hospital of Harbin Medical University

https://orcid.org/0000-0002-8427-9736

\section{Research article}

Keywords: laparoscopy-assisted gastrectomy,open gastrectomy,early gastric cancer,meta-analysis

Posted Date: April 30th, 2020

DOI: https://doi.org/10.21203/rs.3.rs-21112/v1

License: (c) (1) This work is licensed under a Creative Commons Attribution 4.0 International License. Read Full License 


\section{Abstract}

Background There is a controversy for the therapeutic effect of laparoscopy-assisted gastrectomy (LADG) and open gastrectomy for a long time. The meta-analysis in this article evaluates and compares the effectiveness of these two treatments to patients' long-term survival.

Method We searched MEDLINE (PubMed), EMBASE (Ovid) and the Cochrane Library and identified all qualified researches from January 2002 to January 2020. The statistic analysis is performed by Revman 5.3 and Version 3 Comprehensive Meta-analysis. Through the results, we compared the advantages and long-term survival of LADG and ODG.

Result According to the result of 8 randomized controlled trials which involves 2650 patients with early gastric cancer, compared with ODG, LAGD has longer surgery time $(\mathrm{MD}=78.11,95 \% \mathrm{Cl}=59.14-$ $97.07, \mathrm{P}<0.00001)$, less blood loss $(\mathrm{MD}=-100.59,95 \% \mathrm{Cl}=-127.71-73.46, \mathrm{P}<0.00001)$, a shorter incision $(\mathrm{MD}=-12.25,95 \% \mathrm{Cl}=-13.18-11.31, \mathrm{P}<0.00001)$, shorter time to start the first time of flatus $(\mathrm{MD}=-0.66,95 \% \mathrm{Cl}=-1.01-0.32, \mathrm{P}=0.0001)$, shorter hospital stay $(\mathrm{MD}=-0.94,95 \% \mathrm{Cl}=-1.66-0.22, \mathrm{P}=0.01)$, and lower frequency of analgesic utilization ( $M D=-1.69,95 \% \mathrm{Cl}=-2.18-1.21, \mathrm{P}<0.00001)$. However, there is no statistical difference between ODG and LAGD on the number of harvested lymph nodes, time of the first meal, short-term surgical complications, cancer recurrence rate, and long-term survival rate.

Conclusion According to the result of meta-analysis, compared with ODG, LADG has a significant advantage in blood loss in surgery, early rehabilitation, scar development, management of postoperative pain, etc. Meanwhile, LADG and ODG have the same performance on long-term survival. Therefore, we believe LADG is a safe and effective replacement of ODG for early gastric cancer.

\section{Background}

Even the morbidity and mortality dropped significantly, however, gastric cancer (GC) is still an important public health burden globally [1, 2]. 450 thousand cases of gastric cancer were recorded in 2018 which accounts for $10.6 \%$ of all types of cancers. Among these cases, 390 thousand patients were dead from gastric cancer, which accounts for $13.6 \%$ of all deaths from cancer [3]. In recent decades, the diagnosis rate of early gastric cancer has gradually increased due to the improvement of surgical technology and increasing awareness of early diagnosis and treatment, especially in Korea and Japan where has already started gastric cancer screening programs $[4,5]$. This improvement makes the treatment of gastric cancer gradually change from open to minimally invasive procedures. Since Kitano et al. firstly proposed laparoscopic-assisted gastrectomy for the treatment of gastric cancer in 1994 [6], there has been increasing interest in this minimally invasive surgery for the treatment of gastric cancer. Compared with traditional ODG, the advantage of LADG is having smaller skin tips and minimizing wounds to the abdominal wall, thereby reducing intraoperative bleeding and postoperative pain, enabling quicker recovery and also reduces hospitalization costs [7-11]. Therefore, LADG is increasingly used to treat gastric cancer, especially in the early stage [11-13]. However, LADG has not yet become an alternative 
method for treating early gastric cancer worldwide. This is mainly because the clinical results of this method have not been substantially evaluated. Also, because of the complexity of LADG, especially in the reconstruction of the digestive tract and the lymph node dissection, makes it have a longer learning curve and operation time, higher uncertainty of surgical safety and insufficient clearance of lymph nodes [1418]. Also, the increased intra-abdominal pressure caused by pneumoperitoneum may drive tumor cells into the port [19].

In the past 20 years, some randomized controlled trials and retrospective researches comparing the therapeutic result of LADG with ODG for early gastric cancer were reported [20-35]. However, due to the small sample size and lacking long-term results, there is not a completely consistent and conclusive conclusion. Even though the recently published researches of meta-analysis about this theme show that LADG has a significant advantage in treating early gastric cancer, the limitations are still obvious like limited data of RCT, small sample size, short follow-up time. Besides, some meta-analyses [43-45] include data from RCTs and non-RCTs. Non-RCTs may exaggerate the effect of interventions due to deficiencies in the quality of evidence and publication bias. Also, some of the studies include advanced gastric cancer patients or even synthesized data from repeated studies $[12,43,45]$.

Therefore, we combined some recently published RCTs which include big sample size and long-term results and did a systemic meta-analysis. This research did the latest evaluation of the impact of LADG and ODG to the tumor safety and long-term survival for early gastric cancer to help surgeons make more scientific choices when facing patients with early gastric cancer

\section{Method}

\section{Qualification and standard}

The standards of involving RCT researches into meta-analysis are: (1) The research compared the difference between LG and OG in treating gastric cancer. (2) The patient was diagnosed with early gastric cancer, which was defined as cancerous tissues invading the gastric mucosa and submucosa, regardless of the size and lymph node metastasis, and not suffering from other gastric tumors and malignant tumors at other sites. (3) Detailed and practical surgical process, data, long/short-term results should be included in the research. Exclusion criteria: (1) literature review, review, letters, case study or similar researches. (2) Short of data (3) Research published in languages other than English. If multiple studies have been published by the same author or institution, only the study with the largest sample size or quality is selected.

\section{Source of data and retrieval strategies}

This meta-analysis is based on the preferred reporting items for systematic review and meta-analysis (PRISMA) guidelines. A comprehensive literature search was performed from the online databases MEDLINE (PubMed), EMBASE (Ovid) and the Cochrane Library. Also, we expanded the search results by browsing the references in articles. The articles included all full-text publications published between 2002 
and 2019 using the terms including "laparoscopy", "gastrectomy", "gastric cancer" and "randomized controlled trial", etc. The two authors independently conducted literature searches and cross-checked our results.

\section{Research selection and data extraction}

The titles and abstracts of all articles were independently screened by two authors (Zhao Zhai and Shanghai Lou) based on eligibility criteria. Then we conduct a full-text evaluation of all eligible or potentially eligible or ambiguous articles to determine their eligibility. Finally, the final inclusion of the article is determined by consensus or discussing with a third independent reviewer (Yingwei Xue) to resolve the differences. To complete the PRISMA flowchart, all the processes of document selection were recorded. Using standardized tables to extract data, including: (1) characteristics of research (author, year of publication, number of patients, research design, etc.), (2) patient characteristics (gender, age, tumor location, size, and tumor stage, etc.), (3) Short-term and long-term postoperative characteristics (hospital length, postoperative complications, overall survival, DFS, etc.). Copying the data into an Excel spreadsheet and check for errors. When the data is only displayed graphically, use the GetData Graph Digitizer 2.26 software to digitize and extract the data. When raw data is not available, we calculate the data using available coefficients according to the method described in the Cochrane manual.

\section{Risk of bias assessment}

Two authors independently assessed the risk of bias in each study according to the criteria described in Chapter 8 of the Cochrane Intervention System Review Manual [42]. The differences were resolved through discussions with a third reviewer. We conducted bias risk assessments in seven specific areas: random sequence generation, allocation hiding, participant blindness, blindness in outcome evaluation, incomplete outcome data, selective reporting, and other biases. The judgment of the bias risk of the above items was completed by judging as "low risk", "high risk" and "unclear risk" [42].

\section{Statistical Analysis}

The meta-analysis in this research refers to the Review Manager 5.3 (Nordic Cochrane Centre) and Comprehensive Meta-analysis V3. For dichotomous variables (short-term complications, relapse rate, survival rate, etc.), we used a hazard ratio (RR) analysis with a 95\% confidence interval (Cl). For continuous variables (operation time, intraoperative blood loss, wound length, etc.), we used mean difference (MD) analysis with a $95 \%$ confidence interval (CI). If the study does not report the mean and SD values directly, the sample mean and standard deviation are estimated based on the sample size, median, range, or interquartile range in the text. $P<0.05$ was considered statistically significant. Cochrane's $Q$ test and 12 value were used to assess heterogeneity. And heterogeneity is divided into low heterogeneity $(12<50 \%)$ and high heterogeneity $(12 \geq 50 \%)$. When heterogeneity is high $(12 \geq 50 \%)$, sensitivity analysis and subgroup analysis are performed to study clinical heterogeneity. And we use a random-effects model to minimize the impact of heterogeneity between studies. Funnel plots and Egger 
regression tests were used to assess publication bias. The "trim and fill" method is used to adjust the effect of potential publication bias.

\section{Results}

\section{Search results}

We identified 1,559 related studies through search strategies. After removing 175 duplicate publications, we reviewed the titles and abstracts of 1384 studies. 1347 did not meet the eligibility criteria and were excluded. Next, 37 full-text articles were carefully evaluated and reviewed, and a total of 29 studies were removed. Because 12 of these studies are not RCT articles; 5 studies are from the same team publishing data from the same trial; 9 studies are not related to early gastric cancer; 3 studies have no research agreement. Finally, 13 publications containing 8 unique RCTs were found to be eligible [20, 22, 26-31] and included in this meta-analysis. Figure 1 shows the flow chart of the research selection process and the reasons for elimination.

\section{Research Features}

A total of 2675 patients with local early gastric cancer were recruited in 8 RCTs. Laparoscopic surgery and open surgery were compared among patients with early gastric cancer. Table 1 summarizes the main characteristics and results of each trial. Two of the trials were multicentre studies [29, 30], while the remaining trials were conducted at a single-center, including five trials from Japan $[20,22,26,29,31]$ and three trials from South Korea [27, 28, 30]. All trials published between 2002 and 2019, with sample sizes ranging from 28 to 1384, including 1333 and 1342 patients in the LADG and ODG groups separately, all patients included in the trial were Histologically confirmed early gastric adenocarcinoma. In the included trials, the average age in the LADG group was 56 to 63.2 years, and the average age in the ODG group was 54.5 to 62 years. Nobody mass index data were reported in both trials. Billroth-I reconstruction was used in 5 trials $[20,22,26,28,31]$, and the other 3 trials did not limit the type of reconstruction $[27,29,30]$, including Roux-en-Y, Billroth I, Billroth II, and Gastro-gastro. The median follow-up time was 26 to 109 months.

\section{Risk of bias assessment}

In all studies, five trials used appropriate randomly assigned sequences [27-31]. No random alternative is available in other trials. Five trials used appropriate allocation concealment $[20,22,26,30,31]$, two trials were short of information about allocation concealment [27, 28], and one trial did not cover allocation procedures [29]. Because blindness trials between LADG and ODG cases are inherent but the study of Takiguchi et al. [22] describes the process of blinding patients, the risk of implementation bias is reduced. Complete results data, mean of bias risk in selective reporting, etc. Details of the bias assessment risk are shown in Figure 2.

\section{Intraoperative results}


A total of 8 RCT studies provided data on operation time (Figure 3,a). Analysis of the aggregated data showed that the average operation time in the LADG group was 78.11 minutes longer than that in the ODG group ( $\mathrm{MD}=78.11,95 \% \mathrm{Cl}=59.14-97.07, \mathrm{P}<0.00001)$, and significant heterogeneity was found ( 2 $=96 \%, \mathrm{P}<0.00001)$. Sensitivity analysis did not find any tests that had a significant impact on the combined MD. Analysis of the subgroup found that studies with a patient size of $<50$ (MD $=91.91,95 \% \mathrm{Cl}$ $=56.44-127.38, \mathrm{P}<0.00001,4$ studies $)$ and studies with a patient size of $\geq 50(\mathrm{MD}=68.44,95 \% \mathrm{Cl}=$ 41.63-95.25, $P<0.00001,4$ studies $)$ There was no statistical difference $(P=0.30)$. Eight studies showed that the intraoperative blood loss (Figure $3, b$ ) was lower in the LADG group than in the ODG group (MD = $-100.59,95 \% \mathrm{Cl}=-127.71-73.46, \mathrm{P}<0.00001)$. And the heterogeneity between the two groups was obvious $(12=81 \%, \mathrm{P}<0.00001)$. Sensitivity analysis did not find any tests that had a significant impact on the combined MD. The analysis of the subgroup found that the patients were in early gastric cancer $(\mathrm{MD}=-98.35,95 \% \mathrm{Cl}=-149.17-45.53, \mathrm{P}=0.0001,5$ studies $)$ and the patients were in early + advanced gastric cancer $(M D=-96.42,95 \% \mathrm{Cl}=-127.37-65.46, P<0.00001,3$ studies) were statistically different $(P$ $<0.00001)$. Based on the data from 8 studies, it was found that there was no statistically significant difference in intraoperative lymph node retrieval (Figure 3,c) between the LADG group and the ODG group $(\mathrm{MD}=-1.93,95 \% \mathrm{Cl}=-3.85-0.02, \mathrm{P}=0.05)$. And the two groups had high heterogeneity $(12=55 \%, \mathrm{P}=$ $0.03)$, and the sensitivity analysis did not find any tests that had a significant impact on the combined MD. Five studies reported results regarding the length of the incision during surgery (Figure 3,d). The length of the incision in the LADG group was significantly shorter than that in the ODG group (MD = $-12.25,95 \% \mathrm{Cl}=-13.18-11.31, \mathrm{P}<0.00001)$. And there was greater heterogeneity between the studies $(\mathrm{I} 2=$ $91 \%, \mathrm{P}<0.00001)$. Sensitivity analysis did not find any tests that had a significant impact on the combined MD. Subgroup analysis showed studies with patient volume $<50(\mathrm{MD}=-12.31,95 \% \mathrm{Cl}=-13.24-$ 11.39, $\mathrm{P}<0.00001,3$ studies) and studies with patient volume $\geq 50(\mathrm{MD}=-12.25,95 \% \mathrm{Cl}=-13.18-11.31$, $P<0.00001,2$ studies $)$ There was no significant difference $(P=0.84)$.

\section{Postoperative results}

Regarding the discussion of the first flatus time after surgery(Figure 4,a), the results of 6 studies showed that the time in the LADG group was significantly shorter than that in the ODG group (MD $=-0.66,95 \% \mathrm{Cl}$ $=-1.01-0.32, P<0.00001)$. Moreover, the heterogeneity between studies was large $(12=92 \%, P=0.08)$. Sensitivity analysis did not find any tests that had a significant impact on the combined MD. The first postoperative feeding time was reported by 4 studies (Figure 4,b). There was no statistically significant difference between the LADG group and the ODG group ( $M D=-0.48,95 \% \mathrm{Cl}=-1.42-0.46, P=0.31)$. And has a very high heterogeneity $(12=87 \%, \mathrm{P}<0.0001)$. Sensitivity analysis did not show any studies that had a significant effect on the combined MD. Subgroup analysis showed that the Korean study (MD = $-0.40,95 \% \mathrm{Cl}=-1.60-0.20, \mathrm{P}<0.0001,2$ studies) and the Japanese study ( $\mathrm{MD}=-0.55,95 \% \mathrm{Cl}=-3.20-2.09$, $P=0.68,2$ studies $)$ were not statistically different $(P=0.91)$. Six studies reported postoperative hospital stays (Figure 4,C). The LADG group was significantly lower than the ODG group (MD $=-0.94,95 \% \mathrm{Cl}=$ $-1.66-022, P=0.01)$. There was significant heterogeneity between studies $(I 2=82 \%, P<0.0001)$, and sensitivity analysis showed that when either study was deleted, it did not have a significant effect on the combined MD. Three studies gave data on the frequency of postoperative analgesics (Figure 4,d), and the 
results showed that the frequency of use in the LADG group was significantly lower than that in the ODG group ( $\mathrm{MD}=-1.69,95 \% \mathrm{Cl}=-2.18-1.21, \mathrm{P}<0.00001)$. And the heterogeneity is very low $(12=0 \%, \mathrm{P}=0.94)$. Regarding short-term complications after surgery (Figure 5,a), the results of 8 studies showed that there was no statistically significant difference in short-term complications between the two groups $(R R=0.77$, $95 \% \mathrm{Cl}=0.59-1.00, \mathrm{P}=0.05)$, and they were different. The quality is high $(\mathrm{I} 2=51 \%, \mathrm{P}=0.04)$. And among the main short-term complications, respiratory complications $(\mathrm{RR}=0.59,95 \% \mathrm{Cl}=0.32-1.09, \mathrm{P}=0.09$ ), intestinal obstruction $(\mathrm{RR}=0.89,95 \% \mathrm{Cl}=0.29-2.77, \mathrm{P}=0.84)$, Abdominal abscess $(\mathrm{RR}=0.75,95 \% \mathrm{Cl}=$ $0.38-1.50, \mathrm{P}=0.41)$ and anastomotic stenosis $(\mathrm{RR}=0.76,95 \% \mathrm{Cl}=0.15-3.87, \mathrm{P}=0.74)$ were not different. The results of three studies indicate that the WBC counts of the LADG group and the ODG group are the same, and the CRP level of the LADG group is significantly higher than that of the ODG group, but they did not provide accurate data.

\section{Long-term survival}

A total of 7 studies reported the postoperative recurrence rate (Figure $5, b)$. The results showed that there was no statistical difference between the LADG group and the ODG group $(\mathrm{RD}=0.00,95 \% \mathrm{Cl}=-0.01-0.02$, $P=0.84)$, and heterogeneity. Very low $(I 2=0 \%, P=0.999)$. Among them, the number of regional metastasis, peritoneal metastasis, lymph node metastasis, blood-borne metastasis and multiple metastases in the LADG group and ODG group was 12/13, 11/9, 4/5, 8/9, 13/13. A total of 2650 patients in all studies gave survival results (Figure $5, \mathrm{C}$ ). The results showed that there was no significant difference in survival between the two groups $(R R=1.01,95 \% \mathrm{Cl}=0.99-1.03, \mathrm{P}=0.34)$. Very low quality $(I 2=0 \%, P=0.97)$. Three of these studies were followed up for less than 5 years, and the remaining 5 studies provided 5-year survival rates.

\section{Publishing bias}

This study analyzed the publication bias of each result using the funnel plot and the Egger linear regression test. The results showed that only the operation time $(t=4.32, \mathrm{P}=0.005,95 \% \mathrm{Cl}=2.47-8.93$, Egger test, Figure 6) existed. Bias, we used the cut-and-fill method to correct the possibility of publication bias, and the P-value changed from 2.31 to 1.03. It is worth noting that there was no publication bias for long-term survival $(t=0.53, P=0.63,95 \% \mathrm{Cl}=-1.33-1.86)$. The publication bias of other results was lower, all $\mathrm{P}>0.05$.

\section{Discussion}

Since the advent of the first laparoscopic-assisted radical gastrectomy for gastric cancer in 1994, minimally invasive surgery has been widely adopted worldwide $[6,9,10]$. However, LADG has not been fully verified as an alternative method for treating early gastric cancer, which has forced us to find more scientific evidence as soon as possible to prove the safety and effectiveness of LADG. In this study, we reviewed a total of 2650 patients with early gastric cancer in eight randomized controlled trials and compared the results of laparoscopic surgery and open surgery for early gastric cancer. It was found that LADG was superior to ODG in terms of short-term outcomes, and there was no significant difference 
between LADG and ODG in the long-term survival issue. Our meta-analysis provides sufficient evidence for the advantages of LADG in the treatment of early gastric cancer.

Our research shows that LADG is significantly longer than ODG in terms of surgical time, which is the same as the results of several previously published studies [12, 13, 39-42]. It was believed that the longer surgical time is due to the complicated operation procedure of laparoscopic surgery, the long equipment debugging time and the long learning curve. The complexity of the operation is a well-known factor in any surgery, which is considered to be more complicated than other laparoscopic procedures (such as colorectal and laparoscopic cholecystectomy) in LADG technology, because at least 4 important major points need to be identified and intensive lymph node dissection need to be done during the operation. However, the most important part of radical gastric cancer surgery is gastric lymph node dissection. Subgroup analysis showed that compared with the research with less than 50 patients, the research includes more than 50 patients have shorter surgical time although the difference was not statistically significant. We suspect that the increase in the number of patients will extend the doctor's learning curve and ultimately lead to a reduction in surgical time in the LADG group. Studies have also shown [13] that when LADG is conducted by an experienced and skilled surgeon, the operation time of LADG is similar to that of ODG. Therefore, we predict that with the improvement of technology and the accumulation of surgical team experience, the operation time of LADG will be no different or even shorter than ODG.

In other surgical issues, the LADG group did not show any disadvantages. In terms of intraoperative blood loss, LADG was significantly less than ODG. The advantage is that laparoscopy is used to be a replacement of eye observation, and the visual field is enlarged through the display. This can observe the anatomical structure and important blood vessels, prevent accidental bleeding in time, and reduce the chance of secondary surgery [40]. This advantage can also be transferred into reduced perioperative blood transfusions. Therefore, the risk of acute or advanced adverse reactions can be reduced [40]. Small incisions also contribute to the reduction of intraoperative bleeding. This study shows that the length of the LADG incision is significantly shorter than ODG, which will greatly reduce the trauma to the patient. Compared with the traditional large wound, the small incision can reduce the whole body infection, postoperative pain, speeding up the patient's recovery, and the postoperative scar is smaller, which makes the patient's abdomen more beautiful.

We found no significant difference in the number of intraoperative lymph node searches between LADG and ODG. This is different from most of the meta-analysis conclusions previously published $[12,13,37$, 39]. It was known that lymph node dissection is an important part of radical gastric cancer surgery, and the recurrence rate after surgery decreases with the number of less retrieved lymph nodes [40]. Other studies have concluded that the number of intraoperative lymph nodes retrieved by LADG is less than that of ODG. This is because lymph node dissection is a complex process that requires superb laparoscopic skills and a clear understanding of anatomical sites and not all researches are RCT. The eight RCTs included in this research are from South Korea and Japan. Because of the early gastric cancer screening programs in South Korea and Japan, the detection rate of early gastric cancer has exceeded $50 \%[4,5]$. We estimate that this allows surgeons to accumulate rich experience and greatly extend the 
learning curve, resulting in no difference in the intraoperative lymph node detection rate of LADG compared with ODG. This can also prove the tumor safety issue of LADG.

Regarding rapid postoperative recovery, the results of this study show that the first postoperative exhaust time of LADG is significantly shorter than that of ODG, and is statistically significant. Although LADG was not statistically significant compared with ODG in the first feeding time after surgery, LADG was shortened by 0.51 days on average. This is similar to the results of previously published studies [40-42], which all show the advantages of LADG in patients' rapid recovery after surgery. Because LADG can help the operator to observe the eyes through laparoscopy, there is no need to completely open the abdominal cavity of the changer during the operation to obtain the visual field, reducing unnecessary operations during the operation. This results in a significant reduction in the trauma of the operation and has a smaller impact on the gastrointestinal tract, thus reducing the stress response and thus speeding up the patient's gastrointestinal recovery. This has also made LADG significantly less than ODG in terms of hospital stays, which can help patients and their families reduce their financial burden.

According to reports, LADG has an advantage in postoperative pain management. However, the types and methods of administration of painkillers in different regions are different, which results in higher heterogeneity. Therefore, we analyzed the frequency of postoperative painkillers for the three RCTs. The results show that the frequency is significantly lower than the ODG, and the heterogeneity is lower. We believe this is due to the minor trauma of LADG mentioned before. Two of these RCTs $[20,26]$ gave visual analog scales (VAS) for assessing the degree of pain, and the results showed that the VAS scores of patients with LADG at rest on the first and third days after surgery are significantly lower than ODG. This will help patients to return to their daily lives as soon as possible, and it will be psychologically and physiologically beneficial for patients [46]. Also, it can reduce the postoperative pain and pressure of patients, as well as reduce the occurrence of early complications such as abdominal discomfort, nausea, and vomiting. Besides, LADG will effectively reduce the use of abdominal tension sutures and abdominal bandages. This can help patients to cough and sputum as soon as possible, helping the respiratory system to return to normal as soon as possible, thereby reducing the incidence of respiratory complications. [40]. This study showed that the incidence of postoperative complications of LADG was less than ODG, but there was no statistical difference. Several of the major complications included respiratory complications (arrhythmia, pneumonia, pleural effusion), abdominal abscess, intestinal obstruction, and anastomotic stenosis that were not statistically significant between the two groups. This indicates the non-inferiority of LADG compared to ODG in terms of tumor safety.

This study shows that there is no significant difference in the recurrence rate between LADG and ODG. The eight RCTs included in this article all gave survival results. Three of the studies were followed for less than 5 years, and the other 5 studies were followed for more than 5 years, including the two recently published multi-center, high-quality, high-volume randomized controlled trial. A total of 2650 patients were analyzed in this article. The results show that LADG has no statistical difference compared with ODG in terms of long-term survival, and it was longer and shorter 5 years, the same results were obtained. Both heterogeneity and publication bias is low, which fully proves the reliability of this research conclusion. 
However, our meta-analysis still has some limitations. (1) All RCTs included in this article are from South Korea and Japan, excluding other Western countries, and it is uncertain whether the results of this study can be generalized to various countries and ethnicities; (2) Proportion of patients with lymph node metastasis in the patients included in this article It is still small and does not fully reflect the therapeutic effect of LADG on early gastric cancer with lymph node metastasis; (3) There may still be some results with high heterogeneity due to differences in the diagnosis and treatment concepts and learning curves of different doctors.

\section{Conclusion}

According to the results of this meta-analysis, the only disadvantage of LADG compared with ODG is that the operation time is too long, but we believe that with the advancement of technology and the accumulation of surgeon experience, we can completely break this defect. It has obvious advantages in terms of surgical bleeding volume, early rapid recovery, cosmetic effects, and postoperative pain management. We also found that LADG and ODG show similar results on long-term survival. In the end, we believe that LADG is a safe and effective method that can replace ODG in treating early gastric cancer.

\section{Abbreviations}

EGC = early gastric cancer,LADG = laparoscopy-assisted distal gastrectomy,

ODG = open distal gastrectomy,PRISMA=Preferred reporting items for systematic reviews and metaanalyses,LADG = laparoscopy-assisted distal gastrectomy, ODG = open distal gastrectomy,

$\mathrm{Cl}=$ confifidence interval, $\mathrm{RCT}=$ randomized controlled trial, $\mathrm{RD}=$ relative difference, $\mathrm{RR}=$ risk ratio, $\mathrm{SD}=$ standard deviation, $\mathrm{MD}=$ mean difference,HR= Hazard ratio,OS:=Overall survival.

\section{Declarations}

Ethics approval and consent to participate

Not applicable.

Consent for publication

Not applicable.

Availability of data and material

The datasets used and analyzed in the present study are available from the corresponding author upon reasonable request.

Competing interests 
The authors declare that they have no competing interests.

Funding

Not applicable.

Authors'contributions

$Z Z$ designed and drafted the manuscript;SHL and YWX revised the manuscript;ZYZ,XLC,JLG,XY,BLH and $Y Z$ provided guidance and technical assistance in data acquisition and analysis; All authors read and approved the final manuscript.

Acknowledgments

Not applicable.

Author details

${ }^{1}$ Department of Gastroenterological Surgery, Harbin Medical University Cancer Hospital, 150 Haping Road, Harbin, Heilongjiang,150081, P. R. China.

\section{References}

[1]. Bray, F., et al., Global cancer statistics 2018: GLOBOCAN estimates of incidence and mortality worldwide for 36 cancers in 185 countries. CA Cancer J Clin, 2018. 68(6): p. 394-424.

[2]. Siegel, R.L., K.D. Miller and A. Jemal, Cancer statistics, 2019. CA Cancer J Clin, 2019. 69(1): p. 734.

[3]. Feng, R.M., et al., Current cancer situation in China: good or bad news from the 2018 Global Cancer Statistics? Cancer Commun (Lond), 2019. 39(1): p. 22.

[4]. Korean Gastric Cancer Association Nationwide Survey on Gastric Cancer in 2014. J Gastric Cancer, 2016. 16(3): p. 131-140.

[5]. Katai, H., et al., Five-year survival analysis of surgically resected gastric cancer cases in Japan: a retrospective analysis of more than 100,000 patients from the nationwide registry of the Japanese Gastric Cancer Association (2001-2007). Gastric Cancer, 2018. 21(1): p. 144-154.

[6]. Kitano, S., et al., Laparoscopy-assisted Billroth I gastrectomy. Surg Laparosc Endosc, 1994. 4(2): p. $146-8$.

[7]. Kitano, S., et al., Laparoscopic-assisted proximal gastrectomy for early gastric carcinomas. Surg Today, 1999. 29(4): p. 389-91. 
[8]. Dulucq, J.L., et al., Laparoscopic and open gastric resections for malignant lesions: a prospective comparative study. Surg Endosc, 2005. 19(7): p. 933-8.

[9]. Costantino, C.L. and J.T. Mullen, Minimally Invasive Gastric Cancer Surgery. Surg Oncol Clin N Am, 2019. 28(2): p. 201-213.

[10]. Yakoub, D., et al., Laparoscopic-assisted distal gastrectomy for early gastric cancer: is it an alternative to the open approach? Surg Oncol, 2009. 18(4): p. 322-33.

[11]. Son, T. and W.J. Hyung, Laparoscopic gastric cancer surgery: Current evidence and future perspectives. World J Gastroenterol, 2016. 22(2): p. 727-35.

[12]. Liang, Y., et al., Laparoscopic versus open gastrectomy for early distal gastric cancer: a metaanalysis. ANZ J Surg, 2011. 81(10): p. 673-80.

[13]. Ohtani, H., et al., A meta-analysis of randomized controlled trials that compared laparoscopyassisted and open distal gastrectomy for early gastric cancer. J Gastrointest Surg, 2010. 14(6): p. 958-64.

[14]. Zhang, X. and N. Tanigawa, Learning curve of laparoscopic surgery for gastric cancer, a laparoscopic distal gastrectomy-based analysis. Surg Endosc, 2009. 23(6): p. 1259-64.

[15]. Yoo, C.H., et al., Short-term outcomes of laparoscopic-assisted distal gastrectomy for gastric cancer during a surgeon's learning curve period. Surg Endosc, 2009. 23(10): p. 2250-7.

[16]. Rosin, D., O. Brasesco and R.J. Rosenthal, Laparoscopy for gastric tumors. Surg Oncol Clin N Am, 2001. 10(3): p. 511-29.

[17]. Memon, M.A., N. Butler and B. Memon, The issue of lymphadenectomy during laparoscopic gastrectomy for gastric carcinoma. World J Gastrointest Oncol, 2010. 2(2): p. 65-7.

[18]. Shehzad, K., et al., Current status of minimal access surgery for gastric cancer. Surg Oncol, 2007. 16(2): p. 85-98.

[19]. Hopkins, M.P., et al., The effects of carbon dioxide pneumoperitoneum on seeding of tumor in port sites in a rat model. Am J Obstet Gynecol, 1999. 181(6): p. 1329-33; discussion 1333-4.

[20]. Kitano, S., et al., A randomized controlled trial comparing open vs laparoscopy-assisted distal gastrectomy for the treatment of early gastric cancer: an interim report. Surgery, 2002. 131(1 Suppl): $p$. S306-11.

[21]. Fujii, K., et al., T lymphocyte subsets and Th1/Th2 balance after laparoscopy-assisted distal gastrectomy. Surg Endosc, 2003. 17(9): p. 1440-4.

[22]. Hayashi, H., et al., Prospective randomized study of open versus laparoscopy-assisted distal gastrectomy with extraperigastric lymph node dissection for early gastric cancer. Surg Endosc, 2005. 
19(9): p. 1172-6.

[23]. Kim, Y.W., et al., Improved quality of life outcomes after laparoscopy-assisted distal gastrectomy for early gastric cancer: results of a prospective randomized clinical trial. Ann Surg, 2008. 248(5): p. 7217.

[24]. Kim, H.H., et al., Morbidity and mortality of laparoscopic gastrectomy versus open gastrectomy for gastric cancer: an interim report-a phase III multicenter, prospective, randomized Trial (KLASS Trial). Ann Surg, 2010. 251(3): p. 417-20.

[25]. Sakuramoto, S., et al., Laparoscopy versus open distal gastrectomy by expert surgeons for early gastric cancer in Japanese patients: short-term clinical outcomes of a randomized clinical trial. Surg Endosc, 2013. 27(5): p. 1695-705.

[26]. Takiguchi, S., et al., Laparoscopy-assisted distal gastrectomy versus open distal gastrectomy. A prospective randomized single-blind study. World J Surg, 2013. 37(10): p. 2379-86.

[27]. Kim, Y.W., et al., Long-term outcomes of laparoscopy-assisted distal gastrectomy for early gastric cancer: result of a randomized controlled trial (COACT 0301). Surg Endosc, 2013. 27(11): p. 4267-76.

[28]. Lee, J.H., H.S. Han and J.H. Lee, A prospective randomized study comparing open vs laparoscopy-assisted distal gastrectomy in early gastric cancer: early results. Surg Endosc, 2005. 19(2): p. 168-73.

[29]. Katai, H., et al., Survival outcomes after laparoscopy-assisted distal gastrectomy versus open distal gastrectomy with nodal dissection for clinical stage IA or IB gastric cancer (JCOG0912): a multicentre, non-inferiority, phase 3 randomised controlled trial. Lancet Gastroenterol Hepatol, 2020. 5(2): p. $142-151$.

[30]. Kim, H.H., et al., Effect of Laparoscopic Distal Gastrectomy vs Open Distal Gastrectomy on Longterm Survival Among Patients With Stage I Gastric Cancer: The KLASS-01 Randomized Clinical Trial. JAMA Oncol, 2019. 5(4): p. 506-513.

[31]. Yamashita, K., et al., Laparoscopic versus open distal gastrectomy for early gastric cancer in Japan: long-term clinical outcomes of a randomized clinical trial. Surg Today, 2016. 46(6): p. 741-9.

[32]. Takiguchi, S., et al., Laparoscopy-assisted distal gastrectomy versus open distal gastrectomy. A prospective randomized single-blind study. World J Surg, 2013. 37(10): p. 2379-86.

[33]. Kim, Y.W., et al., Long-term outcomes of laparoscopy-assisted distal gastrectomy for early gastric cancer: result of a randomized controlled trial (COACT 0301). Surg Endosc, 2013. 27(11): p. 4267-76.

[34]. Hayashi, H., et al., Prospective randomized study of open versus laparoscopy-assisted distal gastrectomy with extraperigastric lymph node dissection for early gastric cancer. Surg Endosc, 2005. 
19(9): p. 1172-6.

[35]. Lee, J.H., H.S. Han and J.H. Lee, A prospective randomized study comparing open vs laparoscopy-assisted distal gastrectomy in early gastric cancer: early results. Surg Endosc, 2005. 19(2): p. $168-73$.

[36]. Anegawa, G., et al., Laparoscopy-assisted distal gastrectomy for early gastric cancer poses few limitations for selected elderly patients: a single-center experience. Surg Case Rep, 2016. 2(1): p. 56.

[37]. Jiang, L., et al., Laparoscopy-assisted gastrectomy versus open gastrectomy for resectable gastric cancer: an update meta-analysis based on randomized controlled trials. Surg Endosc, 2013. 27(7): p. 2466-80.

[38]. Ohtani, H., et al., A meta-analysis of randomized controlled trials that compared laparoscopyassisted and open distal gastrectomy for early gastric cancer. J Gastrointest Surg, 2010. 14(6): p. 958-64.

[39]. Chen, K., et al., Systematic review and meta-analysis of laparoscopy-assisted and open total gastrectomy for gastric cancer. World J Gastroenterol, 2013. 19(32): p. 5365-76.

[40]. Deng, Y., Y. Zhang and T.K. Guo, Laparoscopy-assisted versus open distal gastrectomy for early gastric cancer: A meta-analysis based on seven randomized controlled trials. Surg Oncol, 2015. 24(2): p. 71-7.

[41]. Lu, W., et al., Long-term clinical outcomes of laparoscopy-assisted distal gastrectomy versus open distal gastrectomy for early gastric cancer: A comprehensive systematic review and meta-analysis of randomized control trials. Medicine (Baltimore), 2016. 95(27): p. e3986.

[42]. Zhang, C.D., et al., Reevaluation of laparoscopic versus open distal gastrectomy for early gastric cancer in Asia: A meta-analysis of randomized controlled trials. Int J Surg, 2018. 56: p. 31-43.

[43]. Peng, J.S., et al., Meta-analysis of laparoscopy-assisted distal gastrectomy and conventional open distal gastrectomy for early gastric cancer. Chin J Cancer, 2010. 29(4): p. 349-54.

[44]. Zeng, Y.K., et al., Laparoscopy-assisted versus open distal gastrectomy for early gastric cancer: evidence from randomized and nonrandomized clinical trials. Ann Surg, 2012. 256(1): p. 39-52.

[45]. Zhang, C.D., et al., Laparoscopic versus open gastrectomy for early gastric cancer in Asia: a meta-analysis. Surg Laparosc Endosc Percutan Tech, 2013. 23(4): p. 365-77.

[46]. Kim, Y.W., et al., Improved quality of life outcomes after laparoscopy-assisted distal gastrectomy for early gastric cancer: results of a prospective randomized clinical trial. Ann Surg, 2008. 248(5): p. 7217. 
Table 1. Characteristics of the studies included in the meta-analyses.

LADG, laparoscopy-assisted distal gastrectomy; ODG, open distal gastrectomy; N/A, not available; \&, mean \pm standard deviation; \#, mean and range; ^ , median and interquartile range.

\begin{tabular}{|c|c|c|c|c|c|c|c|c|c|c|c|}
\hline \multirow[t]{2}{*}{ Study (Year) } & \multirow[t]{2}{*}{ Country } & \multicolumn{2}{|c|}{$\begin{array}{l}\text { Number of } \\
\text { patients }\end{array}$} & \multicolumn{2}{|c|}{$\begin{array}{l}\text { Sex of patients } \\
\text { (Male/Female) }\end{array}$} & \multicolumn{2}{|c|}{ Age of patients } & \multicolumn{2}{|c|}{ Body mass index } & \multirow[t]{2}{*}{ Reconstruction } & \multirow[t]{2}{*}{$\begin{array}{l}\text { Follow Up } \\
\text { (Months) }\end{array}$} \\
\hline & & LADG & ODG & LADG & ODG & LADG & ODG & LADG & ODG & & \\
\hline Kitano (2002) & Japan & 14 & 14 & $9 / 5$ & $8 / 6$ & $63.2 \pm 3.0^{\delta}$ & $60.1 \pm 3.4^{\&}$ & N/A & N/A & Billroth I & 26 \\
\hline Lee (2005) & Korea & 24 & 23 & $11 / 13$ & $15 / 8$ & $\begin{array}{r}56.6 \pm \\
11.2^{\&}\end{array}$ & $59.5 \pm 11.6^{\&}$ & $\mathrm{~N} / \mathrm{A}$ & N/A & Billroth I & 14 \\
\hline $\begin{array}{l}\text { Hayashi } \\
\text { (2005) }\end{array}$ & Japan & 14 & 14 & $9 / 5$ & $13 / 1$ & $\begin{array}{c}56(47- \\
70)^{\#}\end{array}$ & $\begin{array}{c}62(49-75) \\
\#\end{array}$ & $\begin{array}{c}22.8(17.0- \\
25.7){ }^{\#}\end{array}$ & $\begin{array}{c}22.7(17.1- \\
28.4)^{\#}\end{array}$ & Billroth I & 42 \\
\hline Kim (2013) & Korea & 82 & 82 & $47 / 35$ & $52 / 30$ & $\begin{array}{c}56.7(35- \\
80)\end{array}$ & $\begin{array}{c}54.5(28-78) \\
\quad \#\end{array}$ & $24.4 \pm 2.9^{\delta x}$ & $24.3 \pm 3.0^{\& \&}$ & Roux-en-Y; Billroth I; Billroth II & 74.3 \\
\hline $\begin{array}{c}\text { Takiguchi } \\
\text { (2013) }\end{array}$ & Japan & 20 & 20 & $12 / 8$ & $13 / 7$ & $\begin{array}{c}61.5(53.5- \\
71)^{\wedge}\end{array}$ & $\begin{array}{c}62.5(55- \\
67.5)^{\wedge}\end{array}$ & $\begin{array}{c}23.7(22-26) \\
\wedge\end{array}$ & $22.5(21-24)$ & Billroth I & 60 \\
\hline $\begin{array}{l}\text { Yamashita } \\
\text { (2016) }\end{array}$ & Japan & 31 & 32 & $14 / 17$ & $7 / 25$ & $58 \pm 9.6^{\&}$ & $61 \pm 7.6^{\&}$ & $22.6 \pm 3^{\&}$ & $22.6 \pm 3.8^{\&}$ & Billroth I & 63 \\
\hline Kim (2019) & Korea & 673 & 686 & $448 / 225$ & $458 / 228$ & $\begin{array}{r}56.8 \pm \\
10.9^{\&}\end{array}$ & $57.6 \pm 11.3^{\&}$ & $23.8 \pm 3.0^{\delta x}$ & $23.8 \pm 3.0^{\&}$ & Roux-en-Y; Billroth I; Billroth II & 99.8 \\
\hline Katai (2019) & Japan & 462 & 459 & $289 / 173$ & $275 / 184$ & $63(25-80)$ & $\begin{array}{c}64(27-80) \\
\wedge\end{array}$ & $\begin{array}{c}22.3(15.2- \\
28.5) \wedge\end{array}$ & $\begin{array}{l}22.6(16.2 \\
-29.7)^{\wedge}\end{array}$ & $\begin{array}{c}\text { Roux-en-Y; Billroth I; Billroth II; } \\
\text { Gastro-gastro }\end{array}$ & 70.8 \\
\hline
\end{tabular}

Figures 


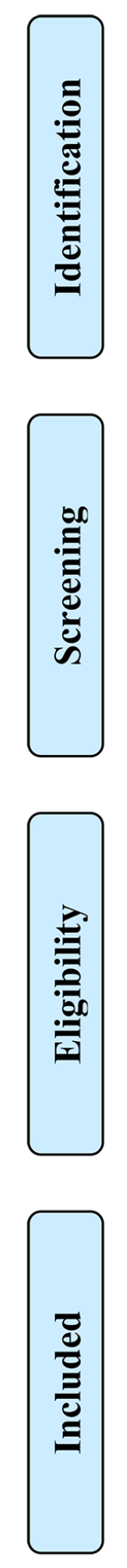

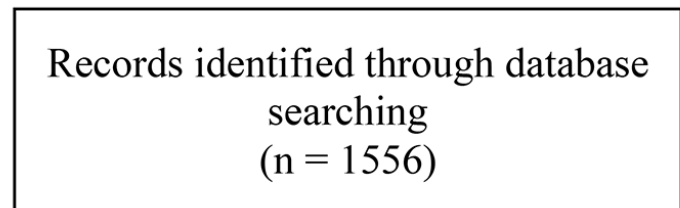

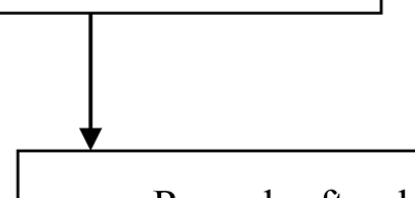

Records after duplicates removed

$$
(\mathrm{n}=1384)
$$
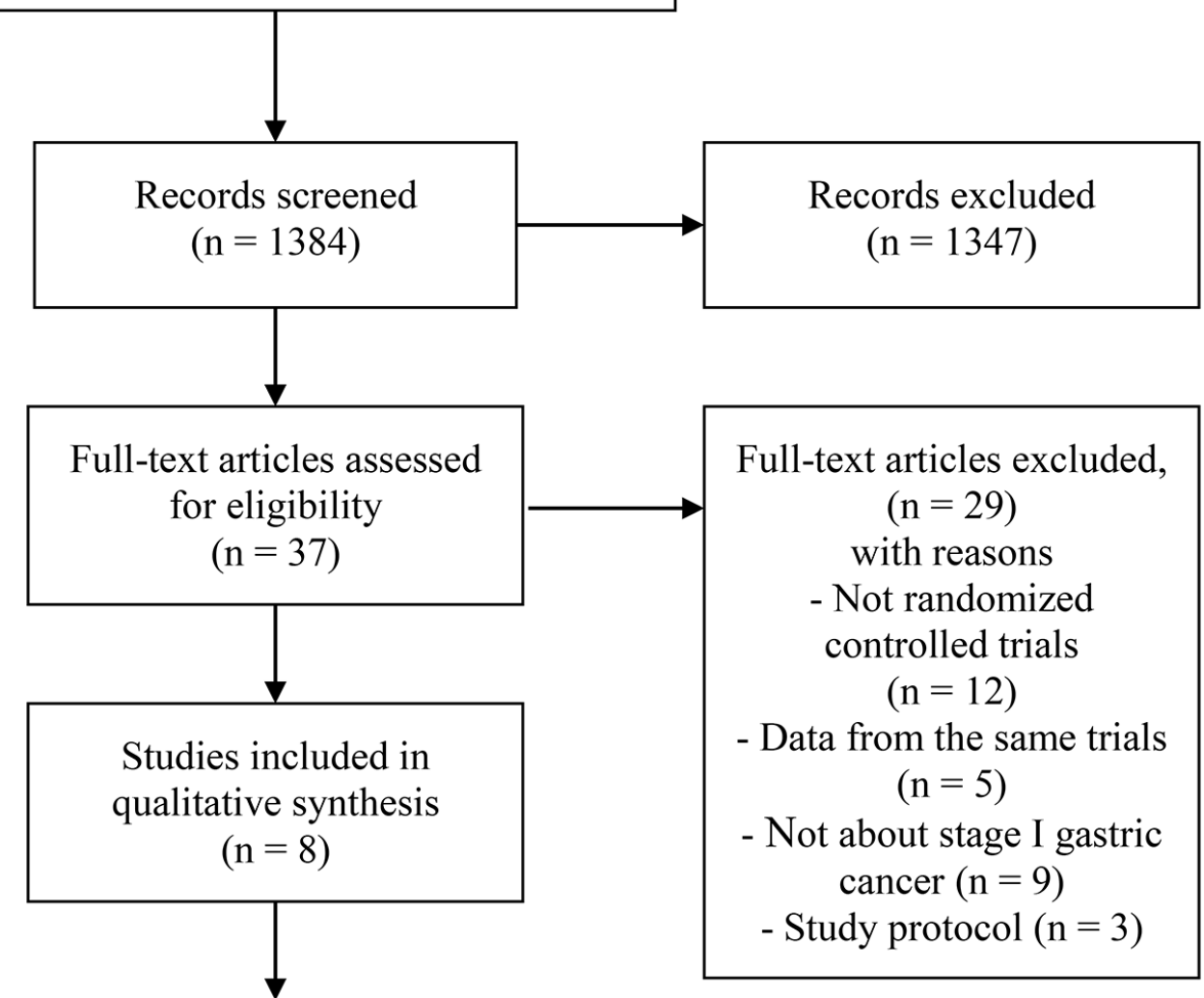

Studies included in quantitative synthesis

(meta-analysis)

$$
(n=8)
$$

Additional records identified through other sources

$$
(\mathrm{n}=3)
$$




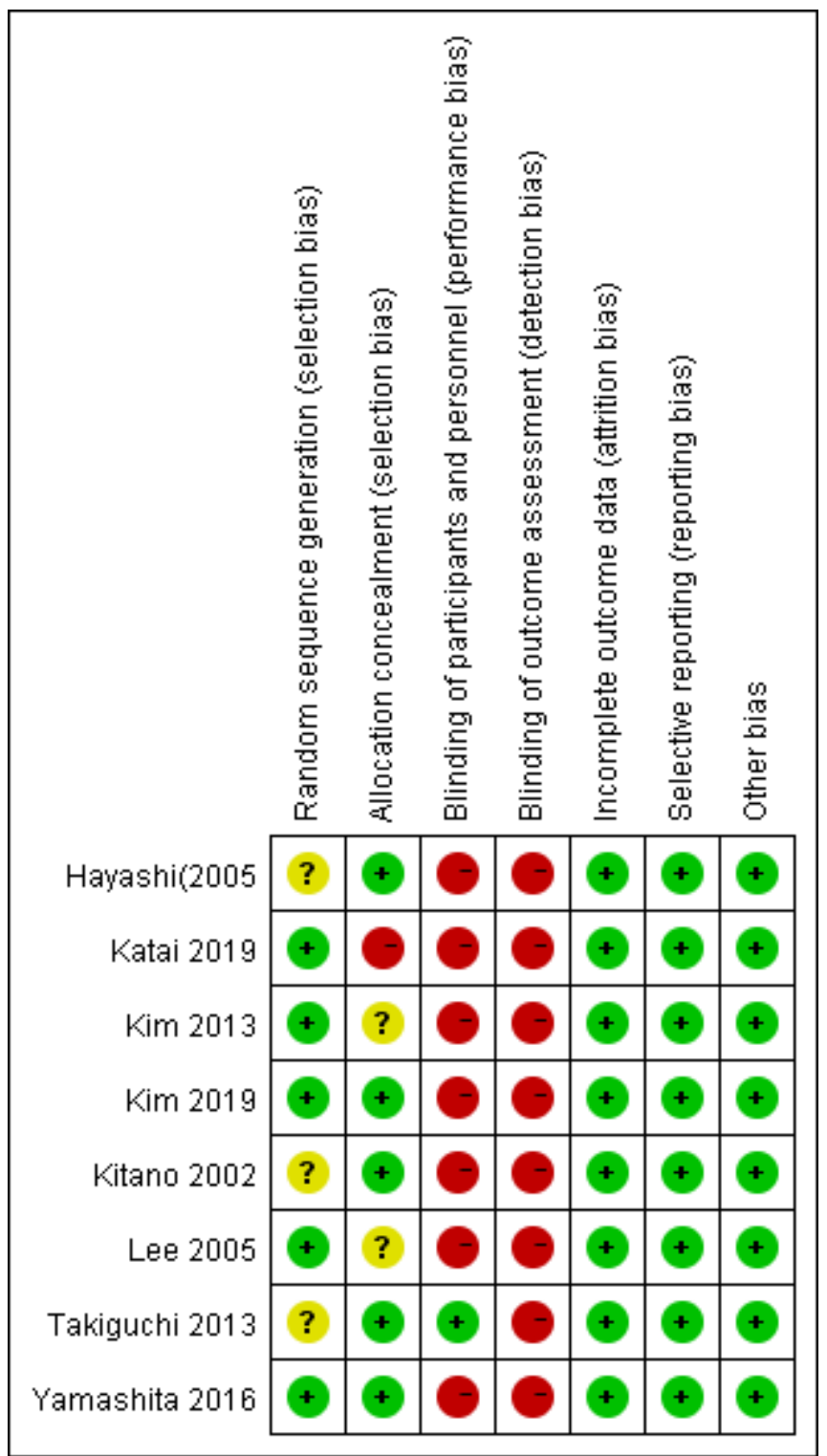

Figure 2

Risk of bias summary: review authors' judgements about each risk of bias item for each included study. +: low risk of bias -: high risk of bias ?: unclear risk of bias. 
A

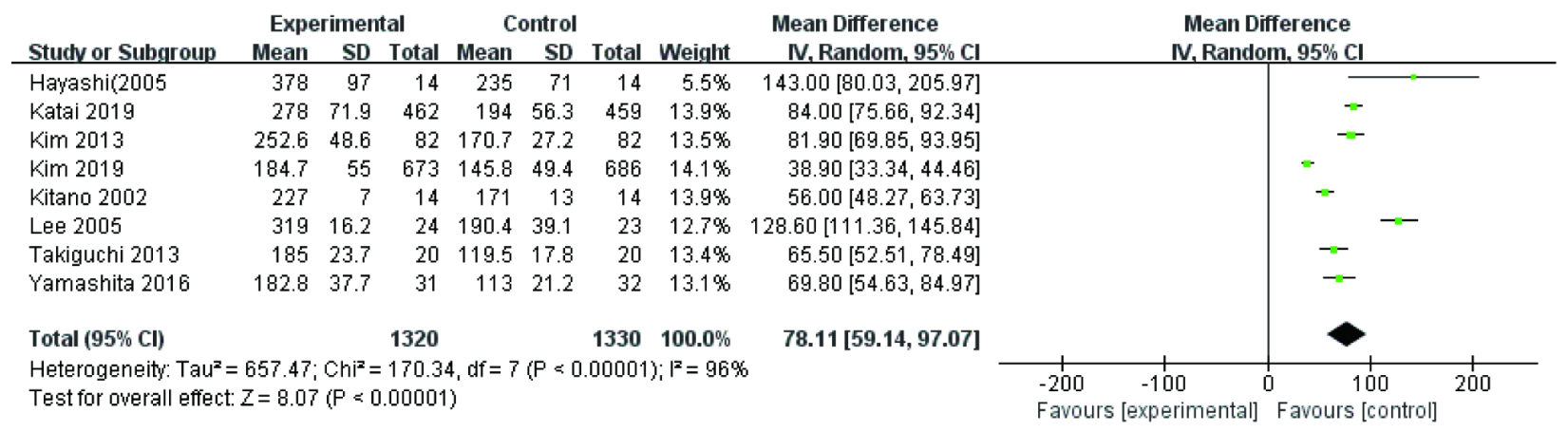

B

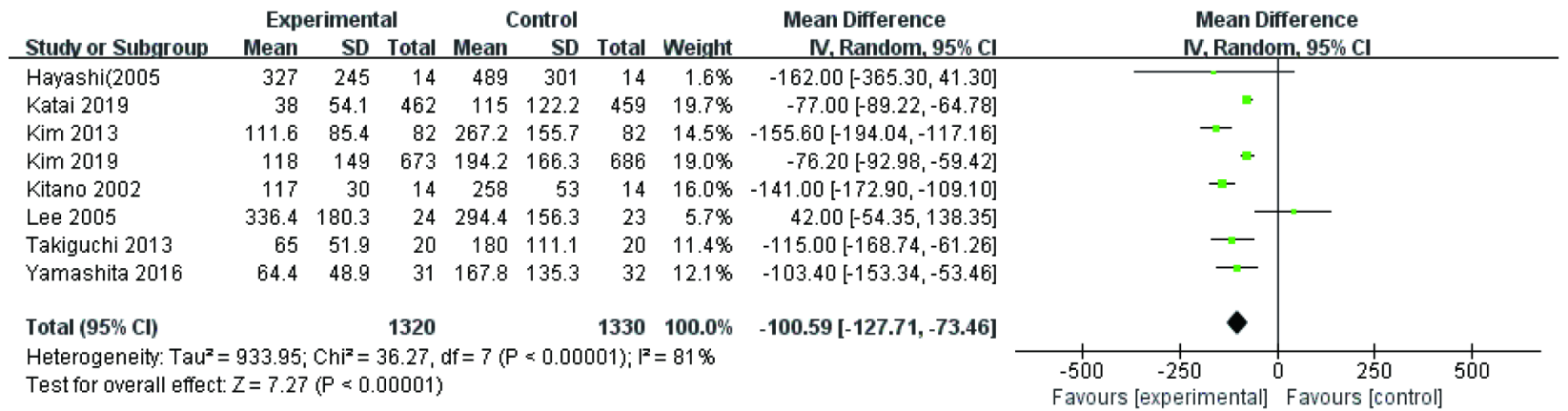

C

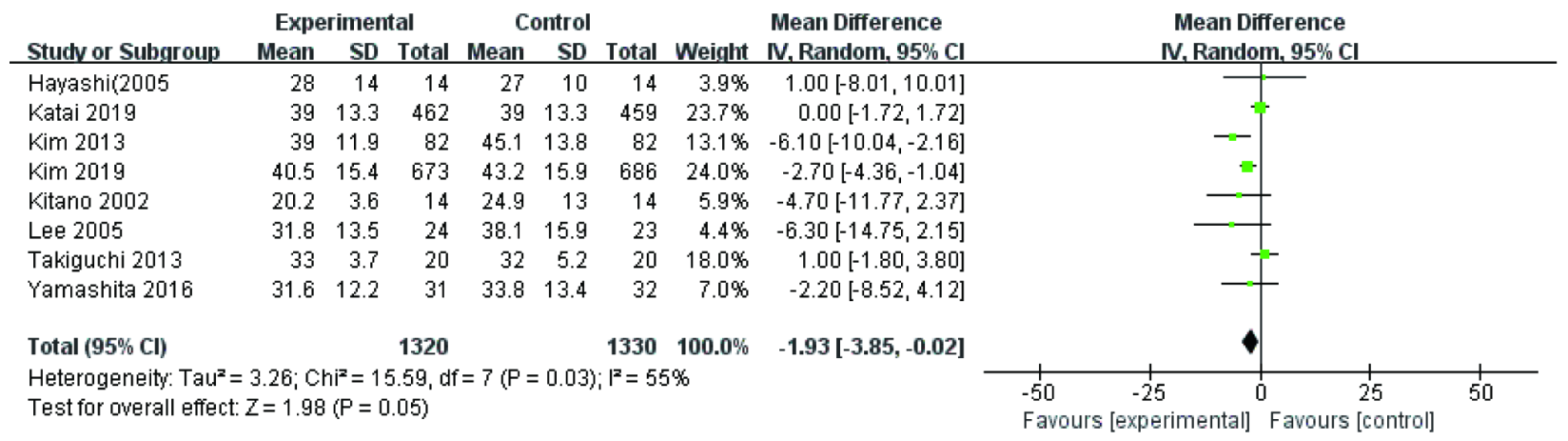

D

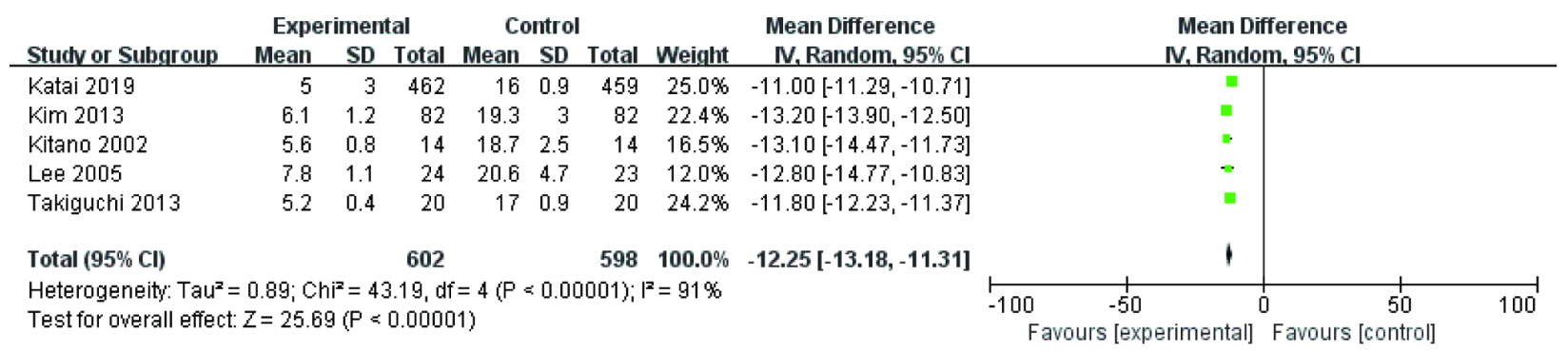

\section{Figure 3}

Meta-analysis of laparoscopy-assisted distal gastrectomy (LADG) and open distal gastrectomy (ODG) for early gastric cancer. a: Operative time (minutes).b:Blood loss (ml).c:Number of harvested lymph nodes.d:length of the incision during surgery SD standard deviation;Cl: confifidence interval; MD mean difference. 
A

\begin{tabular}{|c|c|c|c|c|c|c|c|c|c|c|c|}
\hline \multirow[b]{2}{*}{ Stucty or Subgroup } & \multicolumn{3}{|c|}{ Experimental } & \multicolumn{2}{|c|}{ Control } & \multirow{2}{*}{ Total } & \multirow[b]{2}{*}{ Weight } & \multirow{2}{*}{$\begin{array}{l}\text { Mean Difference } \\
\text { IV, Random, } 95 \% \mathrm{Cl}\end{array}$} & \multirow{2}{*}{\multicolumn{3}{|c|}{$\begin{array}{c}\text { Mean Difference } \\
\text { IV, Random, } 95 \% \mathrm{Cl}\end{array}$}} \\
\hline & Mean & SD & Total & Mean & SD & & & & & & \\
\hline Hayashi(2005 & 3.1 & 1.2 & 14 & 3.9 & 1 & 14 & $10.0 \%$ & $-0.80[-1.62,0.02]$ & & & \\
\hline Katai 2019 & 2 & 0.74 & 462 & 3 & 0.74 & 459 & $22.8 \%$ & $-1.00[-1.10,-0.90]$ & ! & & \\
\hline Kim 2013 & 3.4 & 0.7 & 82 & 3.6 & 0.6 & 82 & $21.5 \%$ & $-0.20[-0.40,-0.00]$ & $=$ & & \\
\hline Kitano 2002 & 2.9 & 0.2 & 14 & 3.9 & 0.2 & 14 & $22.2 \%$ & $-1.00[-1.15,-0.85]$ & $=$ & & \\
\hline Lee 2005 & 3.7 & 1.2 & 24 & 3.8 & 1 & 23 & $13.0 \%$ & $-0.10[-0.73,0.53]$ & & & \\
\hline Takiguchi 2013 & 2 & 1.6 & 20 & 2.75 & 0.8 & 20 & $10.5 \%$ & $-0.75[-1.53,0.03]$ & & & \\
\hline Total $(95 \% \mathrm{Cl})$ & & & 616 & & & 612 & $100.0 \%$ & $-0.66[-1.01,-0.32]$ & & & \\
\hline \multicolumn{9}{|c|}{$\begin{array}{l}\text { Heterogeneity: } \operatorname{Tau}^{2}=0.13 ; \mathrm{Chi}^{2}=59.19, \mathrm{df}=5(\mathrm{P}=0.00001) ; \mathrm{I}^{2}=92 \% \\
\text { Test for overall effect: } Z=3.80(\mathrm{P}=0.0001)\end{array}$} & $\begin{array}{cc}-4 & -2 \\
\text { Favours [experimental] }\end{array}$ & ${ }^{0} \frac{1}{2}$ Favours [c & $\begin{array}{c}4 \\
4 \\
\text { ontrol] }\end{array}$ \\
\hline
\end{tabular}

$\mathrm{B}$

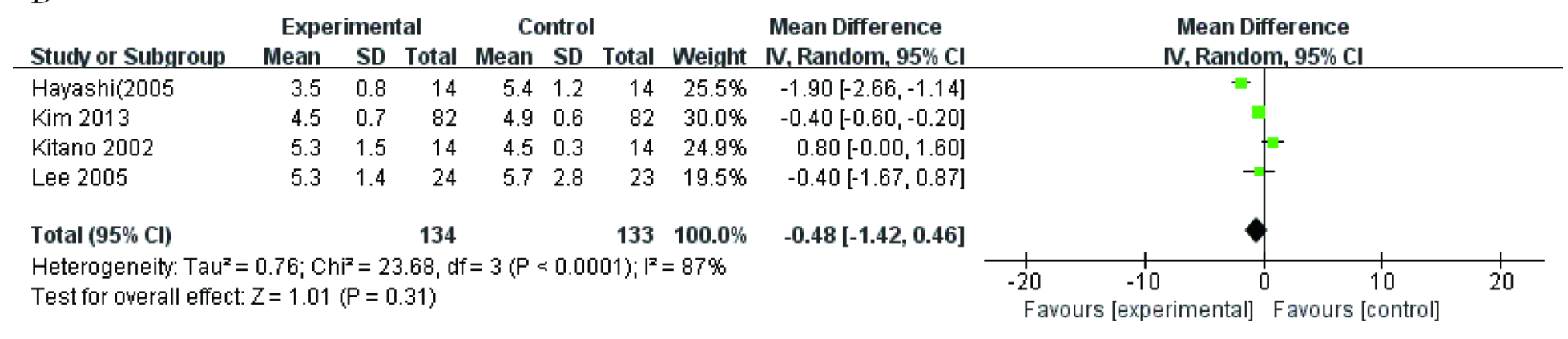

C

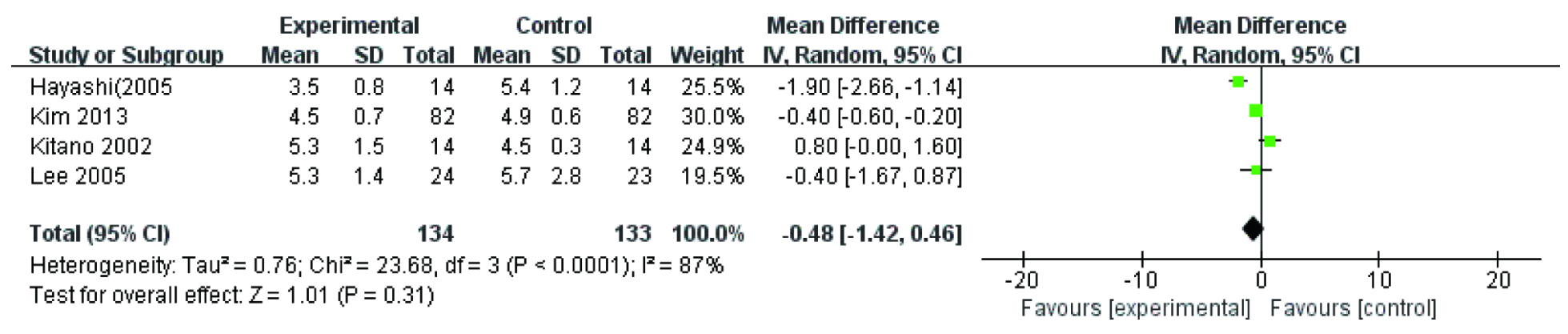

$\mathrm{D}$

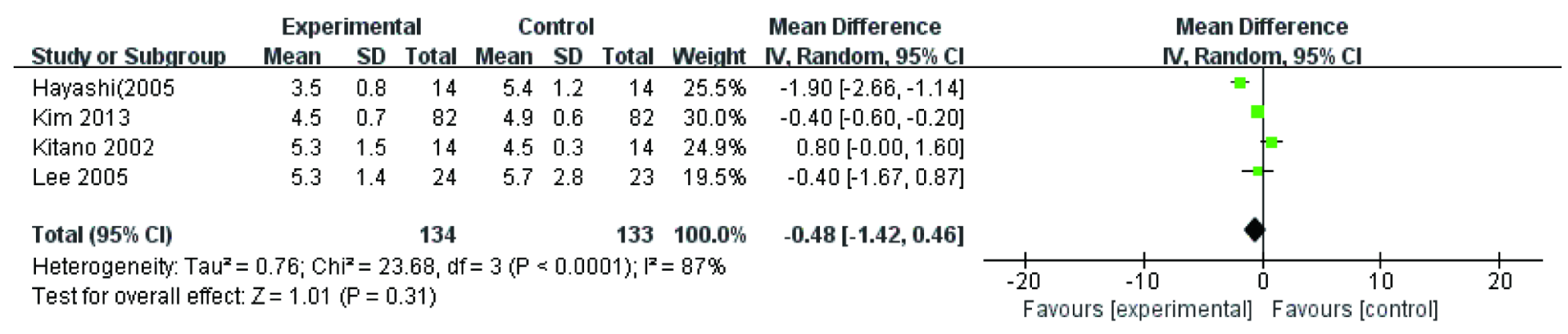

\section{Figure 4}

Meta-analysis of laparoscopy-assisted distal gastrectomy (LADG) and open distal gastrectomy (ODG) for early gastric cancer. a:The first flatus time (days).b.The first feeding time (days).c:Postoperative hospital stay (days).d:frequency of postoperative analgesics. SD standard deviation;Cl confifidence interval; MD mean difference. 
A

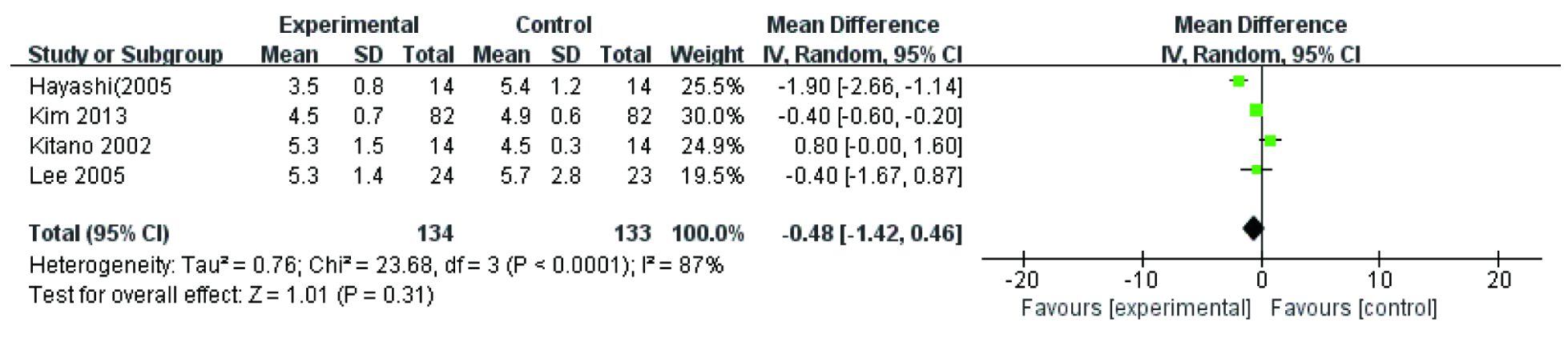

B

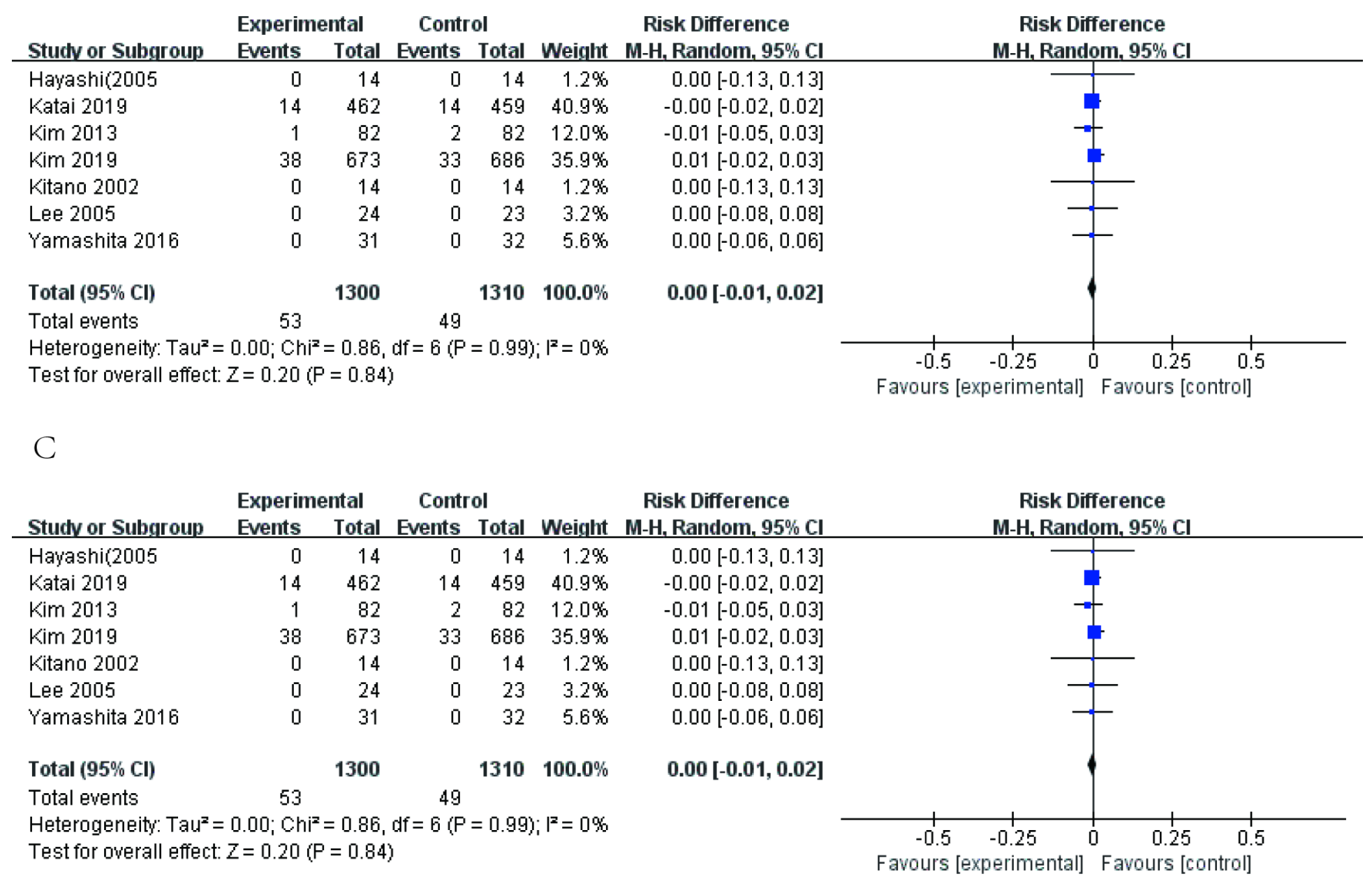

\section{Figure 5}

Meta-analysis of laparoscopy-assisted distal gastrectomy (LADG) and open distal gastrectomy (ODG) for early gastric cancer.a: Rate of postoperative complications.b:The postoperative recurrence rate.c:Survival rate. SD standard deviation; $\mathrm{Cl}$ confifidence interval; $\mathrm{RR}$ risk ratio;RD risk difference. 
Funnel Plot of Standard Error by Std diff in means

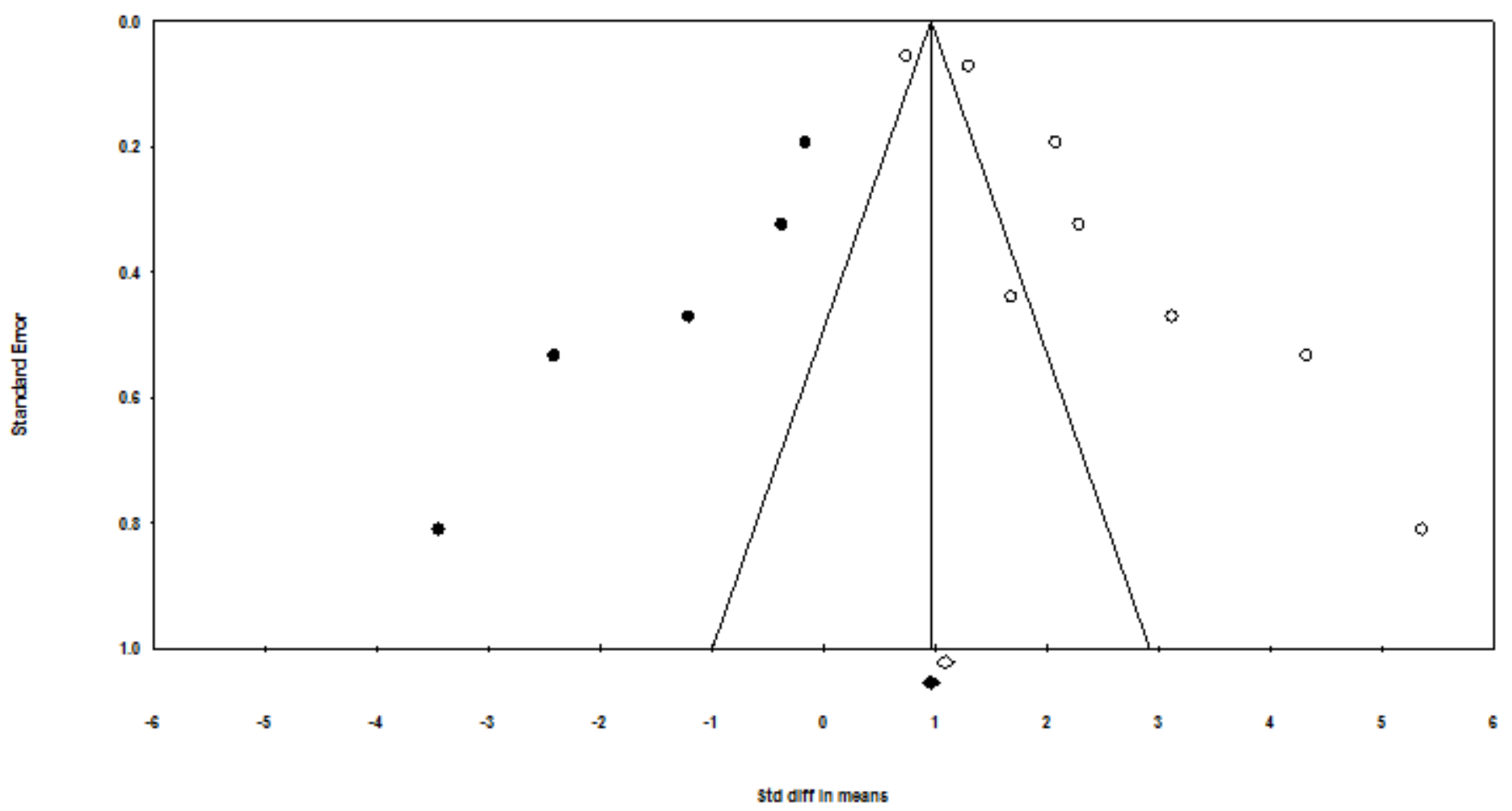

Figure 6

Funnel plot of the operative time.

\section{Supplementary Files}

This is a list of supplementary files associated with this preprint. Click to download.

- ISSMPRISMAChecklist.pdf 